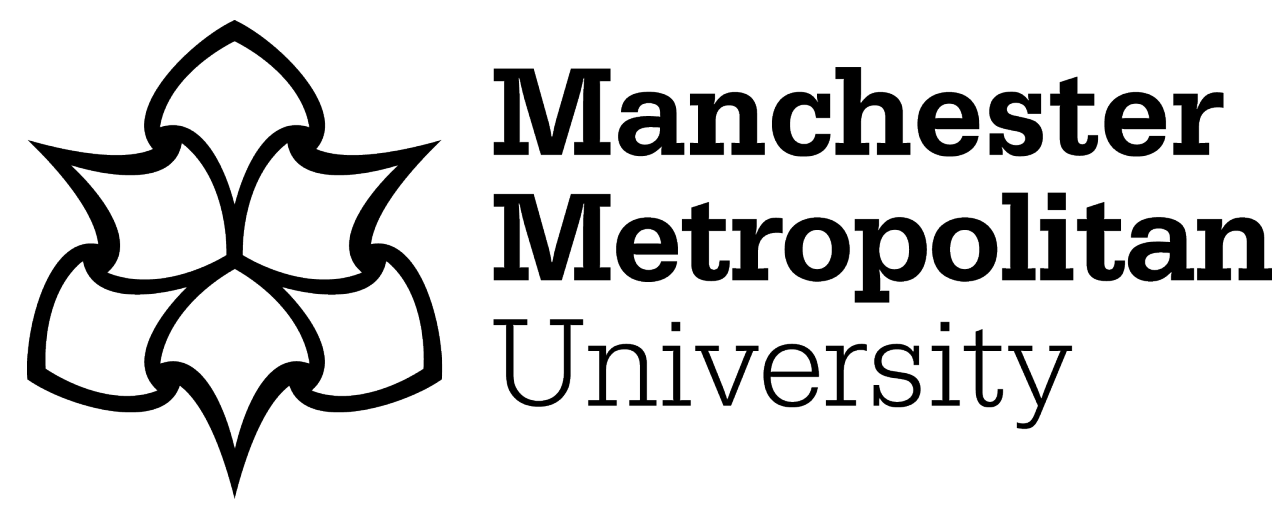

Tedesco, Silvia, Mac Lochlainn, D and Olabi, AG (2014) Particle size reduction optimization of Laminaria spp. biomass for enhanced methane production. Energy, 76. pp. 857-862. ISSN 0360-5442

Downloaded from: https://e-space.mmu.ac.uk/620942/

Version: Accepted Version

Publisher: Elsevier

DOI: https://doi.org/10.1016/j.energy.2014.08.086

Please cite the published version 


\title{
Particle Size Reduction Optimization of Laminaria spp. Biomass for Enhanced Methane Production
}

\author{
Silvia Tedesco ${ }^{*}$, Dubhaltach MacLochlainn ${ }^{\mathrm{a}}$, Abdul Ghani Olabi ${ }^{\mathrm{b}}$ \\ * Department of Mechanical and Manufacturing Engineering, Dublin City University, \\ Glasnevin, Dublin 9, Ireland. Email: silvia.tedesco3@mail.dcu.ie \\ ${ }^{a}$ Department of Mechanical and Manufacturing Engineering, Dublin City University, \\ Glasnevin, Dublin 9, Ireland. Email: d.maclochlainn@nsai.ie \\ b School of Engineering, University of the West of Scotland, Paisley,PA1 2BE, Scotland; \\ email: abdul.olabi@uws.ac.uk
}

\begin{abstract}
Recent studies have reported improved biogas and methane yield from marine biomass when the particle size is mechanically reduced and the specific surface area available to enzymes is increased prior to anaerobic incubation. Although the advantage of reducing the particle size has been identified, an ideal particle size that would offer greater yield with a positive energy balance has not been identified for such substrate to date. As particle size reduction by mechanical means is often highly demanding in energy, this paper attempts to fill this gap for macroalgal biomass by identifying the particle size distribution allowing the highest biogas and methane yields obtained in a previous work. The study estimated that when about $80 \%$ of the particles are sized below $1.6 \mathrm{~mm}^{2}$, a biogas and methane yield improvement of up to $52 \%$ and 53\% respectively can be achieved. The results are discussed in relation to the biogas yield, related methane content and potential inhibitory phenomena occurred during the fermentation.
\end{abstract}

Keywords: Methane; Biogas; Macroalgae; Seaweeds, Mechanical Pre-treatment; Particle Size.

Abbreviations: FA, Free Ammonia; SR Schopper-Riegler number; VFA, Volatile Fatty Acids; VS, Volatile Solids. 
* Corresponding author: Department of Mechanical and Manufacturing Engineering, Dublin City University,

Glasnevin, Dublin 9, Ireland. E-mail address: silvia.tedesco3@mail.dcu.ie. Tel.: +35317007563

a Email: d.maclochlainn@nsai.ie

b Email: abdul.olabi@uws.ac.uk 


\section{Introduction}

Biomass research and developments have been presented in many papers and editorials [1-4]. The mechanical pre-treatment step constitutes a necessary phase to treat any type of biomass prior to any further pre-treatment or anaerobic digestion [5]. A variety of mechanical pretreatments has been developed with the scope of reducing the particle size of the biomass and therefore increasing the specific surface area available for bacterial action [6]. As mentioned in the literature, the particle size is a very important factor positively affecting the biogas production from any type of biomass. A very recent review reports that the particle size reduction is directly correlated with increased biomethanation from lignocellulosic substrates, especially at thermophilic conditions [7]. Such positive effect has been confirmed on very flexible plant biomass such as grass for both biogas [8] and biomethane [9] production. Currently, very comprehensive literature reviews correlating substrates [10], particle size and energy consumption [11] are available for further research and development. However, despite the intensive research of the field, the particle size reduction has often consistently incurred high bioconversion costs, like in the case of lignocellulosic biofuels. Moreover, excessive particle size reduction does not always incur greater yields for all substrates [12]. In this regard, Deublein and Steinhauser [13] claim the relationship between the increased surface area and the increased biogas yield is not linear, as the contribution of very fine particles is lower than that of the bigger ones. This observation is crucial for a critical assessment of the most appropriate particle size to target for a particular substrate, as obtaining finer particles makes the pretreatment more expensive, and may result in negligible yield increases. Seaweeds' bioenergy potential has been identified almost three decades ago [14], and it is now being regarded as the biomass resource of the future generations. 
This work constitutes a continuation of a previous project [15], in which Laminaria spp. biomass were mechanically comminuted by a Hollander beater varying the machine's settings along with the temperature of fermentation in the reactors. The derived biogas and methane yields were used as the responses for a complex system optimisation in order to identify the optimal system input variables by using the response surface methodology (RSM). The highest biogas yield achieved was $685 \mathrm{~mL} \mathrm{gTS}^{-1}$, of which $430 \mathrm{~mL} \mathrm{gTS}^{-1}$ was $\mathrm{CH}_{4}$. In this study, the particle size distribution and the pulp drainability of the feedstock resulting from the proposed pretreatment of [15] are here reported and discussed in relation to the biogas and methane yield. The analyses are performed with the goal of characterizing the most appropriate biogas-producing pulp, referring to the machine's settings used in the previous work, which are provided in Table 1.

\section{Materials and Mechanical Pre-treatment}

Laminaria spp. biomass was collected in Howth, Dublin (Ireland) in June 2013 and used immediately, while the sludge used as inoculum was collected in the waste water treatment plant of Celtic Anglian water Ltd., Ringsend, Dublin (Ireland) and used the same day of the fermentation experiments. The characterization of all the material involved in the experiment is reported in [15], while sludge's characterization is illustrated in Table 2. The equipment used for the particle size reduction consists of a modified Hollander beater, model Reina fully described in previous publications $[15,16]$. A section view of the machine is shown in Figure 1 to provide continuity and allow visualizing one of the study variables, i.e. the machine's gap (MG).

\section{Experimental Methodologies}


The biomass particle size described in the literature for macroalgae [17-19] has been mostly obtained by sieving the treated substrate through a screen of known dimensions, and the particle size is then referred to as mean particle diameter (spherical or squared particles assumed). Particle size analysis revealed this assumption is incorrect in the case of macroalgae’s pretreatment with the Hollander beater, as the resulting particle is extremely irregular in both shape and dimensions. Therefore, in this work the particle size analysis uses the metric of the effective surface area, detected in $\mathrm{mm}^{2}$, and will be hereon referred as maximum frontal surface. The total amount of the different types of macroalgal pulp is 9 and can be achieved varying the machine's gap and the treatment time, as it can be extrapolated by Table 1 .

\subsection{Particle size distribution evaluation}

The maximum frontal surface and distribution of the pulp's particles produced by treating the biomass with the Hollander beater are unique to this specific machine. It was decided to use the superficial surface area in $\mathrm{mm}^{2}$ identified by the means of image processing analysis.

Since the particles will be inspected with a camera, the treated solution samples need to be diluted in order to obtain an acceptable distance between particles. Most samples required a 2:1 dilution with tap water, for more concentrated samples however the dilution was further increased to 6:1. A summary of the dilutions used in this research with respect to the other settings can be seen in Table 2, where the label ID identifies each sample, i.e. G represents the gap setting and $\mathrm{T}$ the treatment duration. In order to express the particle distributions obtained at different machine settings in a comparable way, these dilutions will be taken into account in order to normalize the results appropriately. 
The samples are divided into four $100 \mathrm{~mL}$ batches before they are inspected. Each batch is then poured into a glass tray with a white base where the particles are coaxed apart as much as possible. Various images of the resulting particle spread are then taken, making sure the entire tray is captured. Pictures of the samples were taken using a Canon Powershot G9 camera at high resolution and from the same distance with the aid of a tripod. The camera's specifications and settings are regulated as follows: digital zoom $=1$; compression $=$ superfine; F-stop $=3.5$; exposure time $=1 / 600$ sec; ISO speed $=$ ISO-100; white balance $=$ manual; flash $=$ none; focal length $=22 \mathrm{~mm}$; max aperture $=3.625$. The pictures were then processed using the image processing software ImageJ, which converts each of them into a binary image for easier characterization, as can be seen in Figure 2. ImageJ is able to calculate the area of all individual particles and their quantities. Both these measurements are used to build a statistical size distribution with Microsoft Excel (2010).

\subsection{Substrate’s drainability assessment}

Pulp’s drainability constitutes a very useful tool to associate pulped biomass with eventual digestate's dewaterability issues that arise when scaling up the process in industrial facilities [20]. Above all, the drainability test is fundamental to directly and univocally identify the Hollander beater's operational parameters effects on the particle size reduction. In order to fulfil this purpose, this research employs a Schopper-Riegler apparatus (Figure 3). The Schopper-Riegler method is used to define the degree of beating in the paper industry (for which the Hollander beater is designed), and so it constitutes a valid tool to test the macroalgal pulp’s particle suspension in water obtained in this research. 
The procedure that is followed for the Schopper-Riegler method is the ISO 5267-1:1999 (E) [21]. For each of the 9 samples, a specific Schopper-Riegler number (SR) is identified. The higher the SR, the more drainable the pulp is.

\section{Results and Discussion}

The particle frontal surface distribution and the pulp drainability of the feedstock resulting from the Hollander beater pretreatment are reported and discussed in relation to the biogas and methane yield.

\subsection{Particle size distribution effect on methane formation}

The operational parameters, the resulting biogas yields and its methane content percentages are reported in Table 4, which immediately reveals that samples made of particles with smaller frontal surface (G0T5, G0T10, and G0T15) produce biogas with the highest methane content at $40^{\circ} \mathrm{C}$ and $50^{\circ} \mathrm{C}$, confirming the beneficial effects of the treatment on methane content during biogas production. The particle analysis results arising from the treated samples shown in Table 4 are then plotted for each ID code which represents the parameters setting, i.e. the ID G0T5 is the sample treated at gap $\mathrm{MG}=0$ and $\mathrm{BT}=5$ minutes. The data obtained is provided in Table 5 and presented in Figure 4. The $\mathrm{X}$ axis is presented in logarithmic format to enhance clarity.

Figure 4 reveals that samples G0T15 and G0T10 have a considerably higher amount of particles with small frontal surface compared to the rest. According to the biogas and methane results obtained in Table 4, the worst performing sample (G10T5) proved in the particle size distribution plots to also contain the fewest number of particles. Moreover, samples G5T5 to 
G10T5 can be seen in Table 5 to contain less particles in total, but a greater number of particles in the higher ranges of area.

The total solids concentration in every sample can be considered to be the same as in [15], and the yields comparison in Table 4 was made on the same dry matter basis. This means that the only difference between the samples is the available surface area for enzymatic degradation during the hydrolysis step, which increases with the amount of particles in the sample. For any given volume of material, if it consists of a larger number of smaller particles, it will have a greater overall surface area than a small number of larger particles. The results above are in line with the benefits of the comminution concept reported in literature. It was expected that the highest methane-producing sample achieved in study D would have been G0T15 at $50^{\circ} \mathrm{C}$, instead the best performing sample was G0T10 at $50^{\circ} \mathrm{C}$ which this study found to not have the highest number of particles out of the tested samples. Therefore an excessive reduction in particle size is reached with the proposed pretreatment at settings G0T15 (MG=0, BT=15 minutes), leading to an inhibition effect.

As mentioned in the literature [22-24], if the particle size is below a critical value, the rate of hydrolysis is much greater and therefore a buildup of VFAs may occur in the reactor especially at the beginning of the AD as the biodegradation is more concentrated around the hydrolysis reactions, leading to a drastic drop in $\mathrm{pH}$ [25]. This in turn would have an inhibitory effect on the methanogenic bacteria, and therefore reducing the amount of biogas and methane produced as $\mathrm{pH}$ values below 6.5 have a toxic effect on methanogens [26], making the hydrolysis the rate limiting step in the anaerobic digestion process. A buildup of VFAs may occur also when digesting at thermophilic conditions [27], as a higher temperature can result in higher FA and so in an increased toxicity level and lower process stability, as found in another study on Irish Laminaria spp. digestion [28], where the authors ground the 
biomass to less than $1 \mathrm{~mm}$, and found both biogas and methane productions from mesophilic and thermophilic digestions to be inhibited as $\mathrm{pH}$ levels dropped below 6.5. Drops in $\mathrm{pH}$ when digesting Laminaria spp. were also identified by [29, 30], after excessively reducing the particle sizes of the feedstock. In this research however, the $\mathrm{pH}$ readings carried out across the digestion period did not indicate a consistent decrease in $\mathrm{pH}$ and thus experiencing no inhibition related to excessive VFAs accumulation, despite entering into the thermophilic range and having particle reduction comparable to those studies that experienced inhibition. This lack of $\mathrm{pH}$ inhibition is also reported in [17, 20, 31]. Thus the reason of G0T10's better performance compared with G0T15 cannot be attributed to an excessive accumulation of VFAs. The interaction between $\mathrm{NH}_{3}$, VFAs and $\mathrm{pH}$ determines an "inhibited steady state" [32], where the process is running stably but with a lower methane yield [33]. Ammonia is produced by the biological degradation of the nitrogenous matter. Macroalgal composition usually present high nitrogen content, and consequent ammonia-N inhibition, particularly in thermophilic conditions as highlighted by Chen et al. [32]. High content of nitrogen may also lead to COD/N imbalance, and consequently to inhibition of methanogenesis [34]. The cause of this cannot be fully answered here by the measurements taken and this aspect should be further investigated via analysis of free ammonia $\mathrm{NH}_{3}$ (FA) and VFAs concentration across the whole $\mathrm{AD}$ period. Furthermore, recorded values of $\mathrm{H}_{2} \mathrm{~S}$ were found above $100 \mathrm{ppm}$ in all co-digesting samples. $\mathrm{H}_{2} \mathrm{~S}$ can be regarded as the toxic form of sulfide since it can diffuse into the cell membrane [35]. Therefore, concentration of other inhibitors, such as sulphide, should also be examined to properly identify the reason of such behaviour.

In general, it is proposed that a blend of large and small particles may in fact be the ideal substrate for high biogas yields. The smaller particles would enable an initial rapid rate of 
hydrolysis, which in turn would build up the levels of nutrients suitable for methanogenic bacteria to begin producing biogas. Once these smaller particles are consumed however, the larger particles would provide a reduced surface area, and therefore regulate the subsequent levels of hydrolysis in such a way that all the reactions involved in the digestion are stable and balanced. These requirements seem to be fulfilled by sample G0T10 which allows the highest yields of biogas and methane production. In this sample it was found that the smallest particle size range percentages are very similar (about 20\% each), and more than $80 \%$ of G0T10's macroalgal particles have a specific surface area below the ideal particle size of $1-2 \mathrm{~mm}$ identified by Shell for lignocelluloses [36]. Moreover, the worst performers of Table 4, namely G10T5, G5T10 and G10T15 have a proportion of approximately 50\% of particles below $1 \mathrm{~mm}^{2}$. Thus for optimum yields this proportion should be increased to about $80 \%$. This represents a very important finding, as it appears that seaweed conversion to methane would greatly benefit from a pretreatment capable of achieving targeted particle size ranges. The results show the optimum range to be below a frontal surface of $1.6 \mathrm{~mm}^{2}$, however it is not possible to identify a unique value of an ideal particle's surface area for the Hollander beater. For this reason a drainability study is needed to provide an additional and more accurate metric to characterize the Laminaria spp. pulp obtained by this pretreatment.

\subsection{Drainability characterization results and discussion}

In the fertilizer upgrading process, the digestate needs to be drained of water to reduce its net weight and thus improve the logistics of applying the fertilizer to agricultural land.

Drainability is an extremely important property that facilitates the separation of liquid digestate from its most solid parts and thus reduces the costs of the fertilizer upgrading step [20]. Results of the drainability test are expressed in terms of SR number in Table 6. The SR number has an inversely proportional relationship with drainability, meaning that the biomass 
samples subjected to longer beating times have lesser drainability. Table 6 reveals that the pulp obtained at $\mathrm{MG}=0$ is the least drainable. Pulps treated for 5 minutes are not consistently affected by MG variations (between 78 and 80 SR), while for longer treatment times MG plays a fundamental role in affecting the drainability of the macroalgal pulp. Keeping BT fixed at 10 minutes, reducing MG from 10 to 5 and from 5 to 0 , will both cause a decrease in dewaterability of around 10\%; while keeping BT fixed at 15 minutes and reducing MG from 10 to 5 and from 5 to 0 , will cause a decrease in dewaterability of $13 \%$ on average. A mean decrease of $17.4 \%$ in dewaterability can be observed between coarser pulp (MG=10 with a mean SR of 73) and ideal pulp ( $\mathrm{SR}=88)$. Comparison with the following peer-reviewed studies shows the effect of a pretreatment on the substrate's dewaterability is strictly associated to its nature and morphology. For instance, $\mathrm{Xu}$ et al. [37] studied ultrasonic pretreatment effect on sludge before digestion, and found it has a detrimental effect on dewaterability which resulted in a decrease of about $98 \%$ compared to unsonicated sludge. Drainability values obtained with the Hollander beater in this research show that macroalgal pulp is more than $80 \%$ more dewaterable than sludge after ultrasonic treatment. However, in another study [38], particle size reduction was found to be instead positively correlated with dewaterability of food waste digestate, with an improvement of about $12.5 \%$ (time-to-filter) compared to coarse particles. In this case, the grinding effect (from 8 to $2.5 \mathrm{~mm}$ ) incurred extra specific $\mathrm{CH}_{4}$ yield of 9-34\%, while for macroalgal pulp used in this research values up to $53 \%$ were achieved.

Anaerobic digestion in general has also been found to be beneficial at enhancing the drainability performance of the digestate, particularly when using thermophilic ranges [39]. However, the investigation conducted by Suhartinia et al. on sugar beet pulp digestate shows mesophilic digestion results in poor dewaterability. The authors suggest that the water is 
strongly bound to the digestate possibly due to either colloidal solids or high molecular weight extracellular polymers blinding the filter pores. It is believed this can also be the cause of reduced drainability after treatment with the Hollander beater.

\section{Conclusions}

During the course of this study, the following findings were made:

- The gap size setting of the beater and beating time have a significant effect on the nature of the particles produced by the beater. The beater produces large, irregularly shaped particles at wider gap sizes and shorter beating times, and small particles at narrower gap sizes with longer beating times.

- The highest biogas yields involved particles which were smaller and greater in number. These samples also had a particle surface distribution which was more uniform, namely $80 \%$ below $1.6 \mathrm{~mm}^{2}$ of frontal surface, which represents the recommended threshold of particle size reduction for Laminaria spp. seaweeds.

- Low yields were obtained from material, in which the particles were less in number and relatively large. This is probably due to there being a reduced surface area available for enzymatic degradation.

- It was found that a narrower gap size $(\mathrm{MG}=0)$ and a longer beating time should be used when pre-treating seaweed biomass with the Hollander beater, but at the same time excessive beating times lead to a reduced biogas yield, as do short beating times with wider gap sizes. The reason is not yet clear and cannot be attributed to an excessive accumulation of VFAs. This aspect should be further investigated via analysis of free ammonia (FA), sulfide and VFAs concentration across the whole AD period. 
The smaller the gap MG used for the macroalgae's comminution, the lower is the drainability of the pulp. A high SR value of 88 characterizes the ideal macroalgal pulp for maximized biogas and methane production. Reduced dewaterability of the substrate can affect the cost of digestate upgrading to soil fertilizer, and must be taken into consideration when scaling up the pretreatment process.

\section{Acknowledgements}

This research was supported by the Irish Research Council (IRC) RS/2010/2934, funded by the National Development Plan.

\section{References}

[1] Olabi AG. State of the art on renewable and sustainable energy. Guest Editor's Introduction, Energy 2013;61:2-5.

[2] Olabi AG. Sustainable Energy and Environmental Protection. Guest Editor’s Introduction. Energy 2012;39:2-5.

[3] Olabi AG. The 3rd international conference on sustainable energy and environmental protection SEEP 2009. Guest Editor’s Introduction, Energy 2010;135(12):4508-9.

[4] Clarke A, Prescott T, Khan A, Olabi AG. Causes of breakage and disruption in a homogeniser. Applied Energy 2010;87(12):3680-90.

[5] Salehian P, Karimi K, Zilouei H, Jeihanipour A. Improvement of biogas production from pine wood by alkali pretreatment. Fuel 2013;106:484-9. 
[6] Zadrazil F, Puniya AK. Studies on the effect of particle size on solid-state fermentation of sugarcane bagasse into animal feed using white-rot fungi. Bioresour Technol 1995;54(1):857.

[7] Krishania M, Kumar V, Vijay VK, Malik A. Analysis of different techniques used for improvement of biomethanation process: A review. Fuel 2013;106:1-9.

[8] AS Nizami, NE Korres, JD Murphy. 2009. A review of the integrated process for the production of grass biomethane. Environmental Science and Technology, 43(22), 8496-8508.

[9] AS Nizami, T Thamsiriroj, A Singh, JD Murphy. 2010. The role of leaching and hydrolysis in a two phase grass digestion system. Energy and Fuels, 24 (8), 4549-4559.

[10] Chynoweth DP. Renewable biomethane from land and ocean energy crops and organic wastes. HortScience 2005;40(2):283-6.

[11] Kratky L, Jirout T. Biomass Size Reduction Machines for Enhancing Biogas Production. Chem Eng Technol 2011;34(3):391-9.

[12] Sidiras DK, Koukios EG. Acid Saccharification of Ball-Milled Straw. Biomass 1989;19(4):289-306.

[13] Deublein D, Steinhauser A. Biogas from waste and renewable resources: An introduction. Wiley-vch; 2011.

[14] Tarwadi SJ, Chauhan VD. Seaweed biomass as a source of energy. Energy 1987;12(5):375-8. 
[15] Tedesco S, Marrero Barroso T, Olabi AG. Optimization of mechanical pre-treatment of Laminariaceae spp. biomass-derived biogas. Renewable Energy 2014 2;62:527-34.

[16] Tedesco S, Benyounis KY, Olabi AG. Mechanical pretreatment effects on macroalgaederived biogas production in co-digestion with sludge in Ireland. Energy 2013;61:27-33.

[17] Otsuka K, Yoshino A. A fundamental study on anaerobic digestion of sea lettuce. Proceedings of OCEANS'04. MTTS/IEEE TECHNO-OCEAN'04: IEEE; 2004 November 912; Kobe, Japan. IEEE; Vol. 4, pp. 1770-73.

[18] Bruhn A, Dahl J, Nielsen HB, Nikolaisen L, Rasmussen MB, Markager S, et al. Bioenergy potential of Ulva lactuca: Biomass yield, methane production and combustion. Bioresour Technol 2011;102(3):2595-604.

[19] Vivekanand V, Eijsink VGH, Horn SJ. Biogas production from the brown seaweed Saccharina latissima: thermal pretreatment and codigestion with wheat straw. J Appl Phycol 2012;24(5):1295-301.

[20] Neyens E, Baeyens J. A review of thermal sludge pre-treatment processes to improve dewaterability. J Hazard Mater 2003;98(1-3):51-67.

[21] ISO 5267-1. [1999]. Pulps—Determination of drainability. Part 1: Schopper-Riegler method.

[22] Izumi K, Okishio Y, Nagao N, Niwa C, Yamamoto S, Toda T. Effects of particle size on anaerobic digestion of food waste. Int Biodeterior Biodegrad 2010;64(7):601-8. 
[23] Mshandete A, Bjornsson L, Kivaisi AK, Rubindamayugi MST, Mattiasson B. Effect of particle size on biogas yield from sisal fibre waste. Renewable Energy 2006;31(14):2385-92.

[24] Menardo S, Airoldi G, Balsari P. The effect of particle size and thermal pre-treatment on the methane yield of four agricultural by-products. Bioresour Technol 2012;104:708-14.

[25] Costa JC, Goncalves PR, Nobrel A, Alves MM. Biomethanation potential of macroalgae Ulva spp. and Gracilaria spp. and in co-digestion with waste activated sludge. Bioresour Technol 2012;114:320-6.

[26] Chandra R, Takeuchi H, Hasegawa T. Methane production from lignocellulosic agricultural crop wastes: A review in context to second generation of biofuel production. Renewable \& Sustainable Energy Reviews 2012;16(3):1462-76.

[27] Chen Y, Cheng JJ, Creamer KS. Inhibition of anaerobic digestion process: A review. Bioresour Technol 2008;99(10):4044-64.

[28] Vanegas C, Bartlett J. Anaerobic digestion of Laminaria digitata: The effect of temperature on biogas production and composition. Waste and Biomass Valorization 2012; $12: 1-7$

[29] Hanssen JF, Indergaard M, Ostgaard K, Baevre OA, Pedersen TA, Jensen A. AnaerobicDigestion of Laminaria Spp and Ascophyllum-Nodosum and Application of End Products. Biomass 1987;14(1):1-13.

[30] Adams JMM, Toop TA, Donnison IS, Gallagher JA. Seasonal variation in Laminaria digitata and its impact on biochemical conversion routes to biofuels. Bioresour Technol 2011;102(21):9976-84. 
[31] Gurung A, Van Ginkel SW, Kang W, Qambrani NA, Oh S. Evaluation of marine biomass as a source of methane in batch tests: A lab-scale study. Energy 2012;43(1):396-401.

[32] Chen Y, Cheng JJ, Creamer KS. Inhibition of anaerobic digestion process: A review. Bioresour Technol 2008; 99(10): 4044-64.

[33] Angelidaki I, Ahring BK. Thermophilic digestion of livestock waste: the effect of ammonia. Appl Microbiol Biotechnol 1993; 38: 560-4.

[34] Poggi-Varaldo HM, Rodriguez-Vazquez R, Fernandez-Villagomez G, Esparza-Garcia F. Inhibition of mesophilic solid-substrate anaerobic digestion by ammonia nitrogen. Appl Microbiol Biotechnol 1997; 47:284-91.

[35] Tursman JF, Cork DJ, 1988. Influence of sulfate and sulfate-reducing bacteria on anaerobic digestion technology. In: Mizradi, A., van Wezel, A. (Eds.), Biological Waste Treatment. Alan R. Liss, Inc.

[36] Schell DJ, Harwood C. Milling of Lignocellulosic Biomass - Results of Pilot-Scale Testing. Appl Biochem Biotechnol 1994;45(6):159-68.

[37] Xu HC, He PJ, Yu GH, Shao LM. Effect of ultrasonic pretreatment on anaerobic digestion and its sludge dewaterability. Journal of Environmental Sciences 2011; 23(9): $1472-8$.

[38] Agyeman FO, Tao W. Anaerobic co-digestion of food waste and dairy manure: Effects of food waste particle size and organic loading rate. J Environ Manage 2014; 133: 268-74. 
[39] Suhartinia S, Heavena S, Banksa CJ. Comparison of mesophilic and thermophilic anaerobic digestion of sugar beet pulp: Performance, dewaterability and foam control. Bioresour Technol 2014; 152:202-11. 


\section{Table Captions:}

Table 1. Process variables and values.

Table 2. Sludge characterizations used to determine the sludge contribution (Celtic Anglian Water Ltd.).

Table 3. Operational parameters, dilution factors and sample ID.

Table 4. Variables, sample ID and correlated biogas yield.

Table 5. Particle distribution for equalized volumes of samples.

Table 6. Drainability values obtained by Schopper-Riegler method.

\section{Fig. Captions:}

Fig. 1. Cross sectional view of a Hollander beater (Source: woodwaredesigns.com)

Fig. 2. Examples of fine (a) and coarse (b) particle image and their binary equivalents (c, d).

Fig. 3. Schopper-Riegler apparatus.

Fig. 4. Particle size distribution plot for the 9 samples. 
Table 1. Process variables and values

\begin{tabular}{lccc}
\hline Variables & \multicolumn{3}{c}{ Values } \\
\hline Pre-treatment time (minutes) & 5 & 10 & 15 \\
Machine chopping gap (turns) & 0 & 5 & 10 \\
Incubation temperature $\left({ }^{\circ} \mathrm{C}\right)$ & 30 & 40 & 50 \\
\hline
\end{tabular}


Table 2. Sludge characterizations used to determine the sludge contribution (Celtic Anglian Water Ltd.)

\begin{tabular}{lc}
\hline Parameters & Value \\
\hline Total Solids (TS) [\%] & $4.0 \pm 0.04$ \\
Volatile Solids (VS) [\%] & $69 \pm 1.2$ \\
COD [mg/l] & $68.0 \pm 2.6$ \\
Ammonia [mg/l] & $2.04 \pm 0.01$ \\
Alkalinity [mg/l] & $10.6 \pm 0.40$ \\
VFA’s [mg/l] & $342 \pm 22$ \\
\hline
\end{tabular}


Table 3. Operational parameters, dilution factors and sample ID.

\begin{tabular}{cccc}
\hline $\begin{array}{c}\text { Machine's } \\
\text { Gap } \\
\text { (MG) } \\
\text { [turns] }\end{array}$ & $\begin{array}{c}\text { Beating } \\
\text { Time } \\
\text { (BT) } \\
\text { [minutes] }\end{array}$ & ID & $\begin{array}{c}\text { Dilution } \\
\text { degree }\end{array}$ \\
\hline \multirow{2}{*}{10} & 5 & G10T5 & $2: 1$ \\
& 10 & G10T10 & $2: 1$ \\
& 15 & G10T15 & $2: 1$ \\
& 5 & G5T5 & $2: 1$ \\
5 & 10 & G5T10 & $2: 1$ \\
& 15 & G5T15 & $6: 1$ \\
& 5 & G0T5 & $2: 1$ \\
0 & 10 & G0T10 & $6: 1$ \\
& 15 & G0T15 & $6: 1$ \\
\hline
\end{tabular}


Table 4. Variables, sample ID and correlated yields.

\begin{tabular}{cccccc}
\hline $\begin{array}{c}\text { MG } \\
\text { [turns] }\end{array}$ & $\begin{array}{c}\text { BT } \\
\text { [minutes] }\end{array}$ & $\begin{array}{c}\text { T } \\
{\left[{ }^{\circ} \mathbf{C}\right]}\end{array}$ & ID & $\begin{array}{c}\text { Averaged } \\
\text { biogas } \\
\text { yield } \\
\text { [mL } \mathbf{g T S}^{-1} \text { ] }\end{array}$ & $\begin{array}{c}\mathbf{C H}_{\mathbf{4}}{ }^{*} \\
{[\%]}\end{array}$ \\
\hline \multirow{2}{*}{0} & 5 & 40 & G0T5 & 207.6 & 47 \\
& 10 & $30 ; 50$ & G0T10 & $675.1 ; 651.0$ & $40 ; 48$ \\
& 15 & 40 & G0T15 & 320.4 & 48 \\
5 & 5 & $30 ; 50$ & G5T5 & $503.6 ; 203.6$ & $43 ; 37$ \\
& 10 & 40 & G5T10 & 166.3 & 44 \\
& 15 & $30 ; 50$ & G5T15 & $476.8 ; 255.2$ & $44 ; 41$ \\
10 & 5 & 40 & G10T5 & 138.2 & 42 \\
& 10 & $30 ; 50$ & G10T10 & $527.1 ; 335.5$ & $44 ; 42$ \\
& 15 & 40 & G10T15 & 190.8 & 47 \\
\hline
\end{tabular}

*From [15] including the inoculum's contribution 
Table 5. Particle distribution for equalized volumes of samples.

\begin{tabular}{|c|c|c|c|c|c|c|c|c|c|}
\hline \multirow[b]{2}{*}{$\begin{array}{c}\text { Size range } \\
\left(\mathrm{mm}^{2}\right)\end{array}$} & \multicolumn{9}{|c|}{ Number of particles counted (including dilution factor) } \\
\hline & $\begin{array}{c}\text { G0T } \\
15 \\
\end{array}$ & G0T10 & G0T5 & G5T15 & G5T10 & G5T5 & G10T15 & G10T10 & G10T5 \\
\hline $0.1-0.2$ & 1199 & 1130 & 108 & 295 & 121 & 84 & 81 & 58 & 38 \\
\hline $0.2-0.4$ & 1453 & 1372 & 121 & 382 & 149 & 106 & 96 & 70 & 49 \\
\hline $0.4-0.8$ & 1472 & 1358 & 118 & 480 & 180 & 126 & 105 & 73 & 61 \\
\hline $0.8-1.6$ & 1208 & 1091 & 105 & 500 & 175 & 125 & 97 & 73 & 58 \\
\hline $1.6-3.2$ & 695 & 664 & 84 & 403 & 149 & 108 & 81 & 62 & 56 \\
\hline $3.2-6.4$ & 272 & 321 & 56 & 273 & 109 & 91 & 58 & 43 & 40 \\
\hline $6.4-12.8$ & 83 & 95 & 31 & 143 & 67 & 60 & 44 & 32 & 24 \\
\hline $12.8-25.6$ & 15 & 18 & 8 & 37 & 25 & 35 & 28 & 19 & 10 \\
\hline 25.6-51.2 & 2 & 1 & 2 & 6 & 6 & 16 & 16 & 10 & 12 \\
\hline $51.2-102.4$ & 0 & 0 & 0 & 0 & 1 & 4 & 3 & 2 & 4 \\
\hline $\begin{array}{l}102.4- \\
204.8\end{array}$ & 0 & 0 & 0 & 0 & 0 & 0 & 1 & 1 & 4 \\
\hline $\begin{array}{c}204.8- \\
409.6\end{array}$ & 0 & 0 & 0 & 0 & 0 & 0 & 0 & 1 & 1 \\
\hline $\begin{array}{c}\text { Total } \\
\text { particles }\end{array}$ & 6399 & 6050 & 633 & 2519 & 982 & 755 & 610 & 444 & 357 \\
\hline
\end{tabular}


Table 6. Drainability values obtained by Schopper-Riegler method.

\begin{tabular}{cccc}
\hline $\begin{array}{c}\text { MG } \\
\text { [turns] }\end{array}$ & $\begin{array}{c}\text { BT } \\
\text { [minutes] }\end{array}$ & SR & $\begin{array}{c}\text { Corresponding Volume } \\
\text { [mL] }\end{array}$ \\
\hline \multirow{4}{*}{10} & 5 & 79 & 210 \\
& 10 & 71 & 285 \\
& 15 & 68 & 315 \\
5 & 5 & 78 & 218 \\
5 & 10 & 80 & 200 \\
& 15 & 78 & 218 \\
0 & 5 & 80 & 220 \\
& 10 & 88 & 120 \\
& 15 & 92 & 75 \\
\hline
\end{tabular}




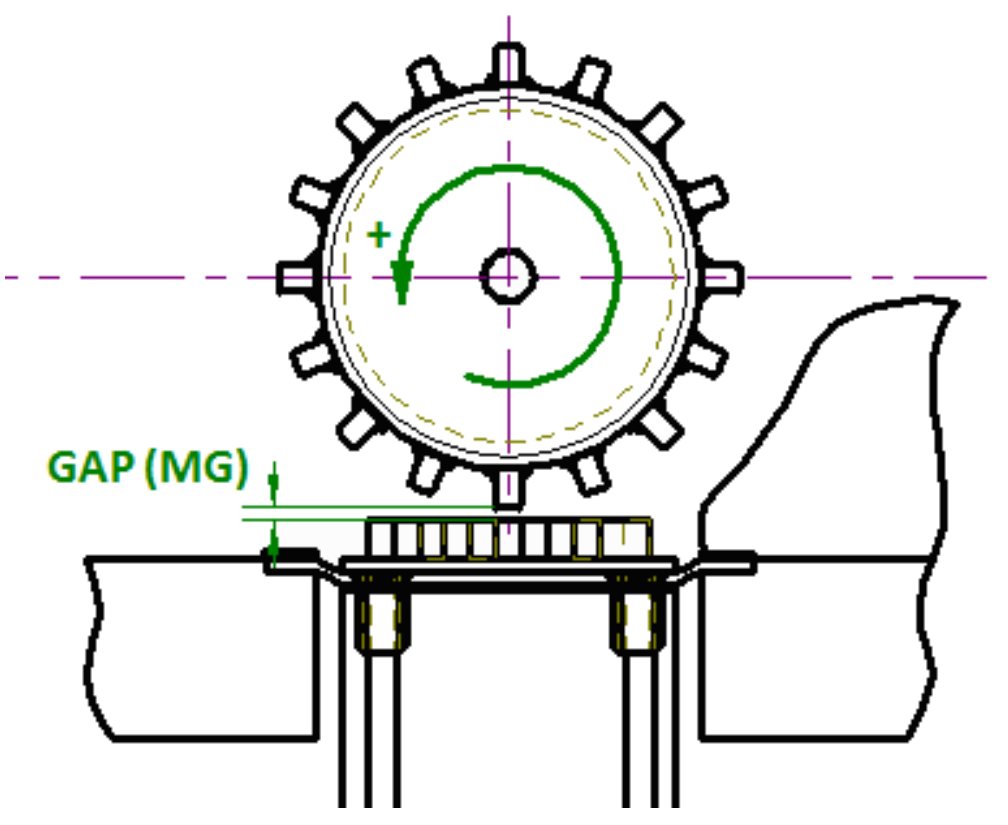

Fig. 1 Cross sectional view of a Hollander beater (Source: woodwaredesigns.com) 


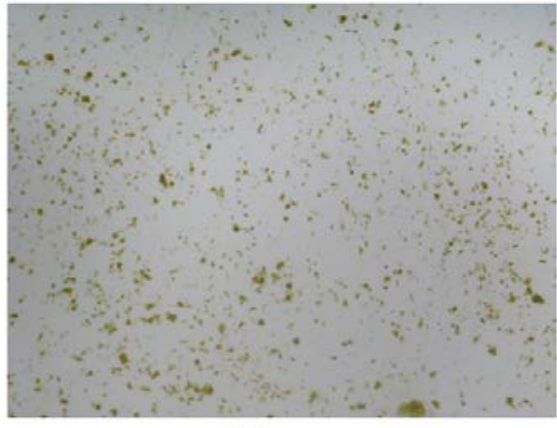

(a)
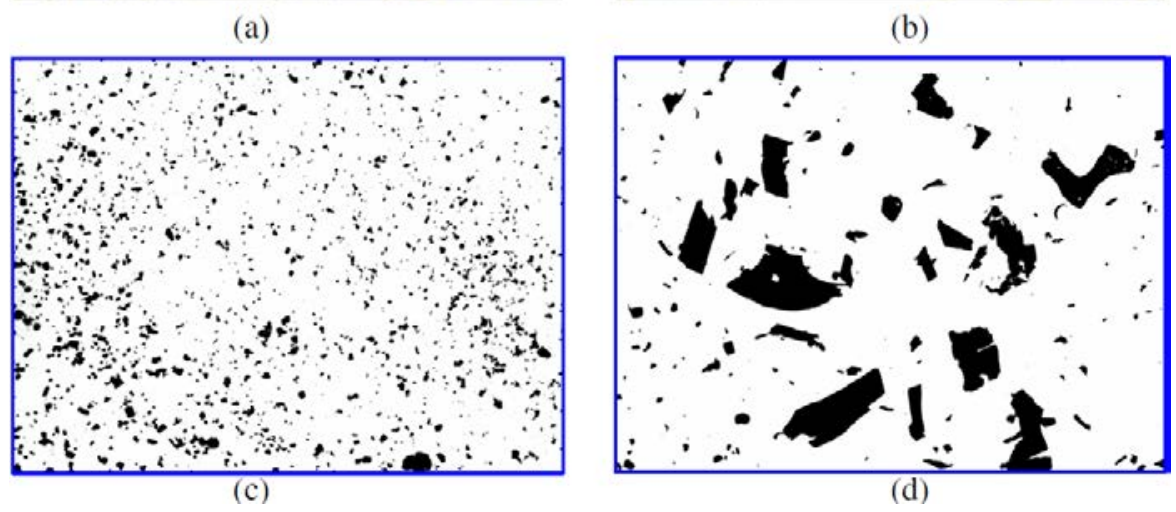

Fig. 2 Examples of fine (a) and coarse (b) particle image and their binary equivalents (c, d). 


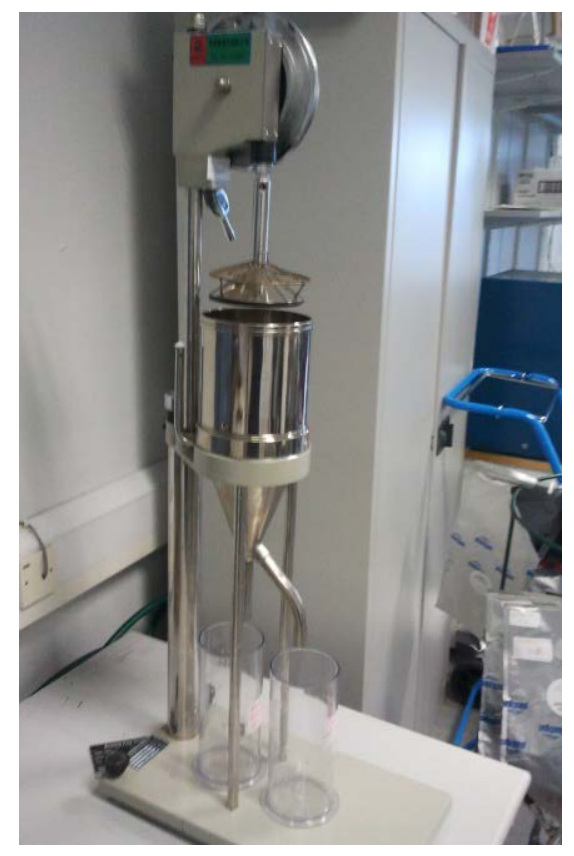

Fig. 3 Schopper-Riegler apparatus. 


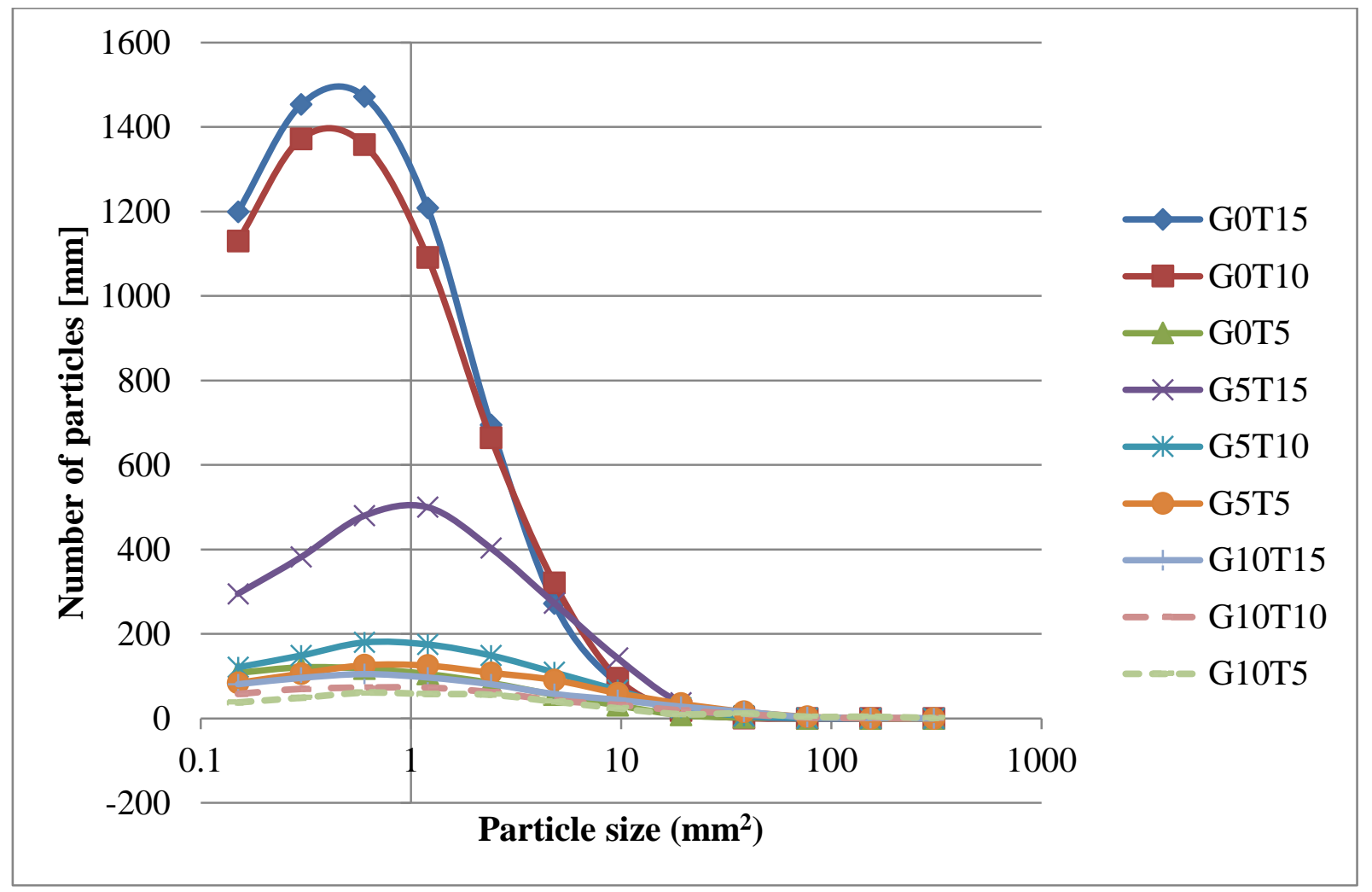

Fig. 4 Particle size distribution plot for the 9 samples. 